\title{
Temporal Analysis of Products Reactor as a Complementary Tool to Study the Mechanism of Some Green Catalytic Reactions
}

\author{
Maria OLEA $^{1,2,3}$, Mizuki TADA ${ }^{2}$, Yasuhiro IWASAWA ${ }^{2}$, \\ Veerle BALCAEN ${ }^{3}$, Isabelle $\mathrm{SACK}^{3}$, Guy B. MARIN ${ }^{3}$, \\ Dirk POELMAN ${ }^{4}$ and Hilde POELMAN ${ }^{4}$ \\ ${ }^{1}$ School of Science and Technology, University of Teesside, \\ Borough Road, Middlesbrough TS1 3BA, U.K. \\ ${ }^{2}$ Department of Chemistry, The University of Tokyo, \\ 7-3-1, Hongo, Bunkyo-ku, Tokyo 113-0033, Japan \\ ${ }^{3}$ Department of Chemical Engineering, Ghent University, \\ Krijgslaan 281, S5, Ghent 9000, Belgium \\ ${ }^{4}$ Department of Solid State Sciences, Ghent University, \\ Krijgslaan 281, S1, Ghent 9000, Belgium
}

Keywords: TAP Reactor, CO Oxidation, VOCs Elimination, $\mathrm{Au} / \mathrm{Ti}(\mathrm{OH})_{4}^{*}$, Vanadia-Based Catalysts

\begin{abstract}
A Temporal Analysis of Products (TAP) reactor was used to study the mechanism of two green catalytic reactions, namely low-temperature $\mathrm{CO}$ oxidation on supported gold catalysts and volatile organic compounds (VOCs) elimination, with propane as model molecule, on vanadia-based catalysts. Single-pulse TAP experiments evidenced a weak and reversible adsorption of $\mathrm{CO}$ on $\mathrm{Au} / \mathrm{Ti}(\mathrm{OH})_{4}^{*}$ catalyst and of propane on vanadiabased catalytic materials obtained by DC magnetron sputter deposition, while $\mathrm{O}_{2}$ adsorption was irreversible on both catalysts. Alternating TAP pulse experiments provided evidence for the nature of oxygen species involved in the oxidation reactions. If the adsorbed oxygen was involved in the $\mathrm{CO}$ oxidation, the lattice oxygen was responsible for the propane oxidation. Multi-pulse TAP experiments assessed the degree of reduction of the catalyst while its influence upon the mechanism is determined by single-pulse experiments. The obtained results will allow the optimal formulation of industrial scale catalysts with applicability to a wide range of industrial processes.
\end{abstract}

\section{Introduction}

Advanced catalysis plays an important role both in pollution control and pollution prevention. Seen as a combination of preparation, experiments, modelling, and simulations, advanced catalysis brings catalytic studies from micro and meso levels to macro level or massive commercialisation of green technologies. For the last few years our attention has been focussed on the understanding of the gold catalysis of low-temperature CO oxidation and on the development of catalytic technologies for volatile organic compounds (VOCs) elimination, towards the final target of improving our environment. The study of the mechanism of the above-mentioned catalytic processes is one of our main objectives.

A temporal analysis of products (TAP) reactor is suitable to perform the study because of its ability to provide trustworthy qualitative and quantitative information about the active sites, the adsorption/desorption features

Received on July 7, 2008; accepted on May 21, 2009. Correspondence concerning this article should be addressed to M. Olea (Email address: M.Olea@tees.ac.uk).

Presented at ISCRE 20 in Kyoto, September, 2008. of the reactants, the reaction sequences and reaction intermediates, and the nature of the oxygen involved. Although TAP results can be sufficient as evidence for proposed mechanisms, in order to get detailed information on the nature of adsorbed species and intermediates, TAP is more often used complementary with other characterization techniques (Olea et al., 2005, 2007).

TAP is a unique experimental transient technique, introduced in 1986, to study the kinetics and the mechanism of heterogeneous catalytic reactions by a pulsed transient response technique (Gleaves and Ebner, 1986; Gleaves et al., 1988). This is accomplished by injecting an extremely narrow gas pulse to an end of a microreactor, while evacuating the other end. In a typical pulsed mode experiment, the pulse mixture contains reactants and an inert gas as internal standard. Consequently, the responses for reactants, products, and inert are monitored by a mass spectrometer as the exit flow time dependencies. TAP experiments use no carrier gas and, as each pulse contains a very small amount of reactant, the gas transport through the reactor is by Knudsen diffusion.

Since its introduction to the scientific community, the TAP system has been applied to investigate a large 
variety of heterogeneous catalytic reactions on one hand and transport in porous catalytic materials on the other hand (Pérez-Ramírez and Kondratenko, 2007).

The TAP technique allows a "state-by-state" screening for chemical characterization of the catalysts (Shekhtman et al., 2003). Therefore, single-pulse and alternating pulse experiments or "state-defining" experiments were performed to characterize the different catalysts' states. A single-pulse experiment consists of a number of single pulses that are injected into the reactor using one pulse valve. The response to a single pulse is monitored at a fixed AMU value. The final response is averaged over the number of pulses to increase the signal-to-noise ratio. The pulse spacing between the single pulses comprising a single-pulse experiment is chosen sufficiently large to avoid accumulation of adsorbed species at the catalyst surface. Single-pulse experiments can provide information on adsorption/desorption features of different species. Alternating pulse or pump-probe experiments consists in sending single pulses of two reactant gases from two separate pulse valves over the catalyst. By varying the time interval between the subsequent single pulses, information on life time and reactivity of adsorbed species formed on the first pulse (pump pulse) and probed on the second pulse (probe pulse) can be obtained. In a multi-pulse experiment a large train of pulses of only one reactant is sent over the catalyst surface inducing changes. Such type of experiment is called "statealtering" and is often followed by a "state-defining" experiment in order to redefine the catalyst state. The former experiment reveals information on the capacity of the catalyst to store certain species.

In this paper, the TAP technique was used to clarify the controversial mechanism for low-temperature $\mathrm{CO}$ oxidation on supported Au catalysts. Even though in the last two decades supported gold nanoparticles have received much attention especially for the scientific interest of their applications to catalysis, the details of the mechanism for $\mathrm{CO}$ oxidation are still under debate. The difficulty in the elucidation of the reaction mechanism may be explained by the high sensitivity of the activity of these catalysts to preparation methods and operation conditions (Gupta and Tripathi, 1999; Bond, 2001; Daniells et al., 2005).

Next to the research of $\mathrm{CO}$ oxidation on gold catalysts, the TAP reactor was employed to characterize the behavior of the newly prepared vanadia-based catalysts foreseen for the catalytic elimination of VOCs. In particular, the effect of the degree of reduction, vanadia loading, and support upon the mechanism was elucidated based on TAP results.

Although the TAP data on the adsorption mechanism over supported Au catalyst were already published (Olea et al., 2001a), they were used within this paper in comparison with the new TAP data obtained over vanadia-based catalysts, as this comparison led to pointing out different adsorption mechanisms and different oxygen adsorption species involved in the oxidation reactions studied.

This paper focuses on the most significant TAP evidence supporting the proposed mechanisms over the catalysts under study.

\section{Experimental}

\subsection{Catalysts preparation}

1.1.1 Gold catalyst As-precipitated wet titanium hydroxide $\mathrm{Ti}(\mathrm{OH})_{4}^{*}$ was obtained by hydrolysis of $\mathrm{Ti}\left(\mathrm{O}^{i} \mathrm{C}_{3} \mathrm{H}_{7}\right)_{4}\left(99.999 \%\right.$ purity) with an aqueous $\mathrm{NH}_{3}$ solution. The precipitate was then filtrated off and washed with deionized water until $\mathrm{pH}$ became 7.0. The as-precipitated wet $\mathrm{Ti}(\mathrm{OH})_{4}^{*}$ was impregnated with an acetone solution of triphenylphosphine gold nitrate $\mathrm{Au}\left(\mathrm{PPh}_{3}\right)\left(\mathrm{NO}_{3}\right)$ under vigorous stirring, followed by vacuum drying to remove the solvent at room temperature. The obtained sample was heated to $673 \mathrm{~K}$ at a ramping rate of $4 \mathrm{~K} \mathrm{~min}^{-1}$ and kept at this temperature for $4 \mathrm{~h}$ in a flow of air $\left(30 \mathrm{~mL} \mathrm{~min}{ }^{-1}\right)$. The catalyst thus obtained is denoted as $\mathrm{Au} / \mathrm{Ti}(\mathrm{OH})_{4}^{*}$ (Yuan et al., 1996).

1.1.2 Vanadia-based catalysts The preparation of vanadia-based catalysts has been described in detail elsewhere (Poelman et al., 2007a, 2007b). DC magnetron sputter deposition of the active layers, vanadia or titania and vanadia, in an argon/oxygen atmosphere, was applied onto spherical inert beads, $\mathrm{SiO}_{2}-\mathrm{ZrO}_{2}$ (33 wt $\% \mathrm{SiO}_{2}, 67$ $\mathrm{wt} \% \mathrm{ZrO}_{2}, 250-425 \mu \mathrm{m}$ diameter), using a rotating drum for overall exposure of the particle support. Coating with $\mathrm{TiO} x$ was performed using a rotatable cylindrical magnetron $(\phi 14 \mathrm{~cm}$, length $=45 \mathrm{~cm})$ with a plasma sprayed rutile target, in reactive sputter mode. To ensure complete coverage of the surface with titania, a deposition time of 180 min was applied. For the vanadia sputter depositions, two plane circular magnetrons $(\phi 5 \mathrm{~cm})$ with ceramic $\mathrm{V}_{2} \mathrm{O}_{3}$ targets were used. Vanadia layers were deposited in reactive sputtering mode with different deposition times. Variation of the deposition time yielded catalysts with varying amounts of vanadia. After each deposition (titania, as well as vanadia), an ex situ annealing treatment at $623 \mathrm{~K}$ for $1 \mathrm{~h}$ in air was applied, in order to favour full oxidation and possibly crystallize the coating. Samples were labeled following the consecutive steps in their synthesis; for example, TiV150 was first coated with titania for $180 \mathrm{~min}$, and then coated with vanadia for 150 $\min$.

\subsection{TAP experiments}

Transient pulse studies of the low-temperature $\mathrm{CO}$ oxidation were performed using a home-made TAP set-up available at The University of Tokyo (Olea et al., 2001a). TAP studies over vanadia-based catalysts were performed with a TAP system available at Ghent University, described in detail by Gleaves et al. (1988).

Briefly, the apparatus consists of a catalytic microreactor, a gas delivery system for introduction of either high-speed gas pulses or a continuous flow of gas, a 

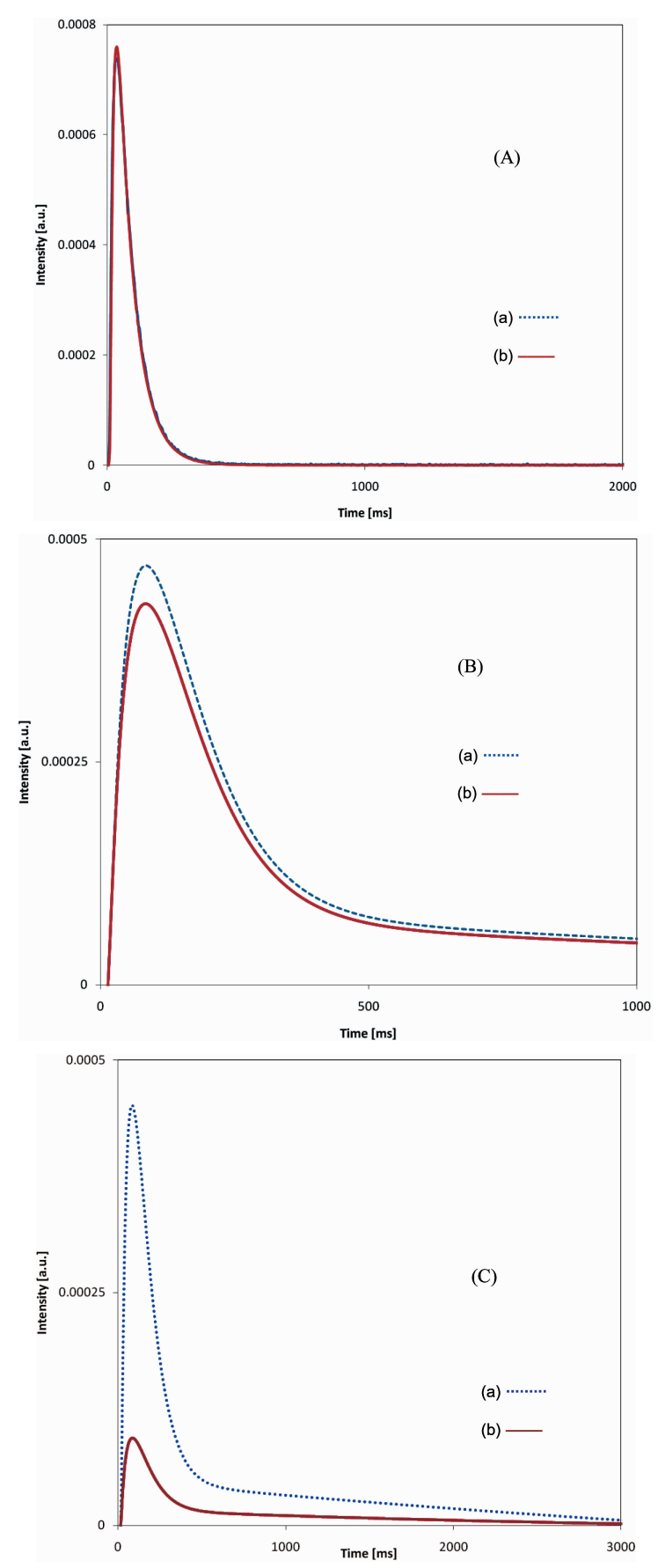

Fig. 1 Single-pulse responses of $\mathrm{CO}(\mathrm{A}), \mathrm{O}_{2}$ (B) and $\mathrm{CO}_{2}(\mathrm{C})$ compared with the $\mathrm{Ar}$ response over $\mathrm{Au} / \mathrm{Ti}(\mathrm{OH})_{4}^{*}$ catalyst, at $373 \mathrm{~K}$ : (a) $\mathrm{Ar}$; (b) $\mathrm{CO}(\mathrm{A})$, $\mathrm{O}_{2}(\mathrm{~B})$, or $\mathrm{CO}_{2}(\mathrm{C})$

high-throughput, high vacuum system and a computercontrolled quadrupole mass spectrometer. The microreactor is made from either a stainless steel tube whose diameter and length are $2 \mathrm{~mm}$ and $25 \mathrm{~mm}$, respectively (Tokyo TAP set-up) or a quartz tube, $45 \mathrm{~mm}$ long and $5 \mathrm{~mm}$ in diameter (Ghent TAP set-up). The reactor can be heated up to $973 \mathrm{~K}$ by cartilage heaters (Tokyo) or by placing it in a furnace (Ghent); the maximum temperature in this case is $1173 \mathrm{~K}$. The two high-speed pulse valves can be operated at the interval up to 50 pulses per second. The minimum pulse width is $200 \mu$ s for the Tokyo set-up and $100 \mu$ s for the Ghent set-up. Unlike a conventional pulsed reactor experiment, a carrier gas is not employed in TAP. Instead, at sufficiently small pulse intensities the gas molecules move through the reactor via Knudsen diffusion in which transport is well defined. In the Knudsen regime the product pulse shape is independent of pulseintensity. Therefore, Knudsen diffusion can be and it is used as a "measuring stick" for extracting kinetic information. In the TAP experiments, the observed quantities are the outlet flows of gas molecules and related integral quantities, e.g., moments. The zeroth moment represents the total amount of gas molecules that emerge from the reactor, and the ratio of the first and the zeroth moments represents the average residence time of gas molecules in the reactor.

The analysis of the products was performed in TAP mode. As such, the mass spectrometer is adjusted to detect only one mass and the intensity of that mass is then recorded as a function of time.

The number of molecules admitted per single pulse was in the range of $10^{14}-10^{15}$ molecules, allowing the transport in the reactor to occur only through Knudsen diffusion.

Although the analysis of TAP experimental data provided qualitative, semi-quantitative, and quantitative information about the above-mentioned processes, the paper presents only the qualitative and some semiquantitative results.

\section{Results and Discussion}

\subsection{Single-pulse TAP experiments providing evi- dence for adsorption/desorption features}

2.1.1 Gold catalyst About $32 \mathrm{mg}$ of $\mathrm{Au} / \mathrm{Ti}(\mathrm{OH})_{4}^{*}$ catalyst with a particle size of 250-425 $\mu \mathrm{m}$ was loaded in the micro-reactor resulting in a catalyst bed length of approximately $10 \mathrm{~mm}$. Single-pulse experiments with $\mathrm{CO} / \mathrm{Ar}, \mathrm{O}_{2} / \mathrm{Ar}$, and $\mathrm{CO}_{2} / \mathrm{Ar}$, all mixtures in a 9:1 reactant gas to Ar ratio, were performed at 298, 373, and $473 \mathrm{~K}$. By comparing the single-pulse responses of the reactants with the Ar response, the adsorption features of the three species were assessed. Figure 1 presents the normalized responses at $373 \mathrm{~K}$, for $\mathrm{CO}(\mathrm{A}), \mathrm{O}_{2}(\mathrm{~B})$, and $\mathrm{CO}_{2}(\mathrm{C})$ compared with Ar. The behavior of $\mathrm{CO}$ is hardly different from the Ar behavior. The two responses almost overlap. This means that $\mathrm{CO}$ is only weakly and reversibly adsorbed on the catalyst. The $\mathrm{O}_{2}$ response however lies completely under the Ar response, pointing to an irreversible adsorption. Moreover, the amount of oxygen reacted on the catalyst during adsorption can be evaluated from the difference between the two responses. From this point of view, $\mathrm{CO}_{2}$ reacted even more while irreversibly adsorbing on the catalyst. The same behavior of the three species was observed for the other two temperatures, 298 


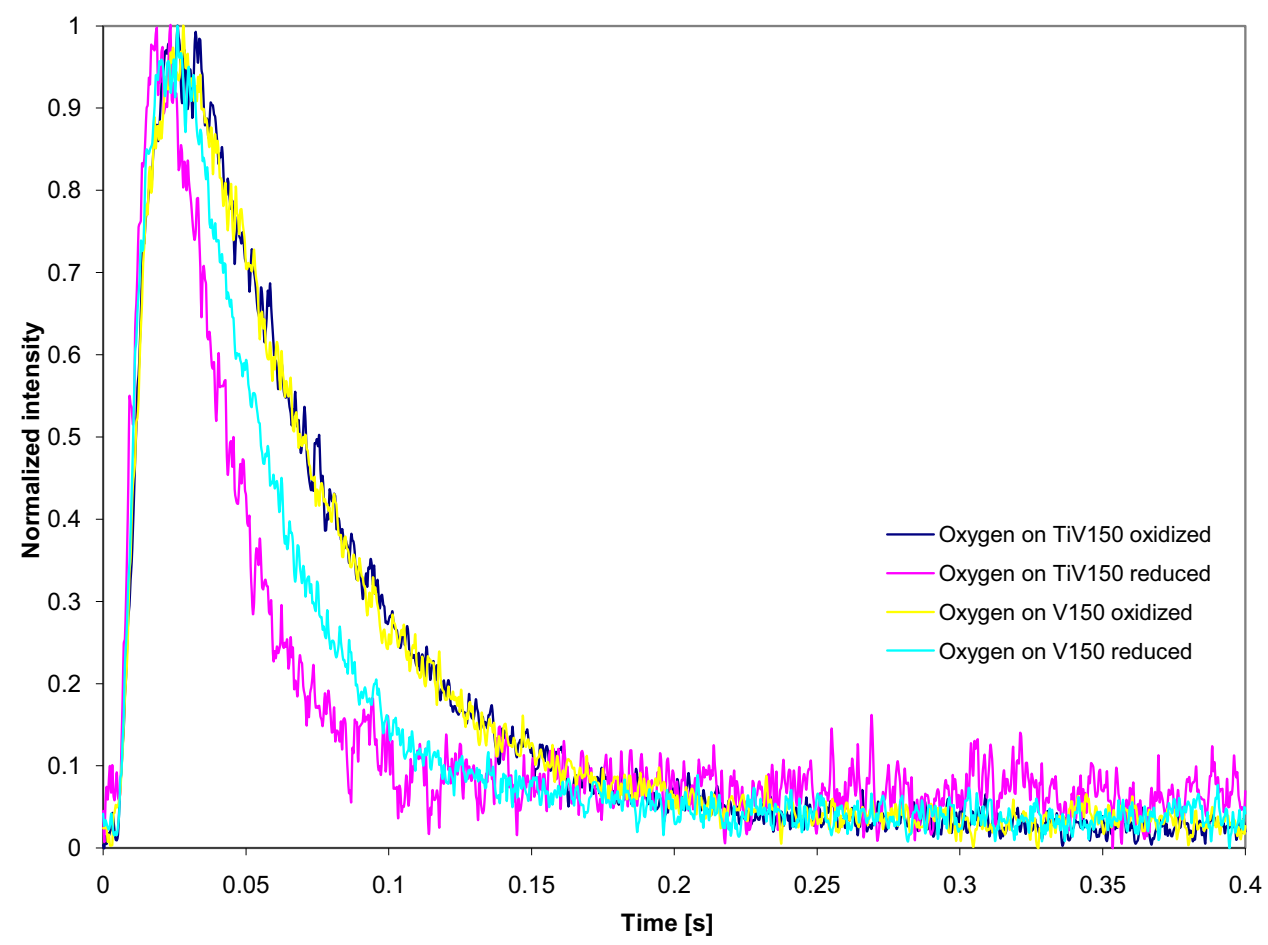

Fig. 2 Normalized response of oxygen as a function of time at $773 \mathrm{~K}$

and $473 \mathrm{~K}$ (results not shown). In addition, single-pulse TAP experiments with labeled oxygen undoubtedly confirmed that oxygen is molecularly adsorbed as an identical response for the three isotopomers, ${ }^{18} \mathrm{O}_{2},{ }^{18} \mathrm{O}^{16} \mathrm{O}$, and ${ }^{16} \mathrm{O}_{2}$, was obtained (result not shown) (Olea et al., 2001b). If $\mathrm{O}_{2}$ dissociated to atomic oxygen at the catalyst surface, oxygen exchange with lattice oxygen atoms would have occurred and the peak time for the three isotopomers would have been different. Although through TAP experiments not a direct evidence whether oxygen molecule is dissociatively or non-dissociatively adsorbed on supported Au catalysts was obtained, the TAP results are the most convincing evidence for molecularly adsorbed oxygen until now (Haruta and Daté, 2001). Besides TAP experiments, systematic oxygen isotope exchange experiments along with $\mathrm{O}_{2}$-TPD, ESR, and FT-IR on $\mathrm{TiO}_{2}$ - and $\mathrm{Fe}_{2} \mathrm{O}_{3}$-supported $\mathrm{Au}$ catalysts, which were prepared from $\mathrm{Au}\left(\mathrm{PPh}_{3}\right)\left(\mathrm{NO}_{3}\right)$ as the precursor for $\mathrm{Au}$ particles and as-precipitated metal hydroxides as precursors for metal-oxide supports, were performed. All indicated that reversibly adsorbed $\mathrm{CO}$ reacted with molecularly and strong (nearly irreversible) adsorbed $\mathrm{O}_{2}$ (probably as $\mathrm{O}_{2}^{-}$) on oxygen vacancies on the support (Liu et al., 1999a, 1999b). There still remains an important argument, whether the dissociation of molecularly adsorbed oxygen takes place before reacting with $\mathrm{CO}$ adsorbed on the $\mathrm{Au}$ surfaces or the dissociation takes place through reaction. In the latter case, the formation of carbonate intermediate can be excluded because no ${ }^{18} \mathrm{O}$ scrambling to produce $\mathrm{C}^{18} \mathrm{O}_{2}$ takes place.
2.1.2 Vanadia-based catalysts The catalyst bed, containing maximum $1 \mathrm{~g}$ of catalyst, was packed in the reactor between two layers of quartz of the same particle size $(250-425 \mu \mathrm{m})$. Single-pulse experiments with propane and oxygen were performed at $773 \mathrm{~K}$. Oxygen was irreversibly adsorbed on all studied catalysts, irrespective of support or vanadia loading. However, the oxidation state of the catalyst and the type of support influence the strength of oxygen adsorption as seen in Figure 2 for catalysts with vanadia deposition time of 150 min. No such influence was observed for the propane weak adsorption (results not shown). The oxidation state of the catalyst was assessed through the degree of reduction, $R^{0}$, defined as the ratio of the number of oxygen molecules taken up by the catalyst to the surface vanadia content (Sack et al., 2004). This oxygen uptake is determined from multi-pulse experiments with oxygen (see Figure 4) over the catalysts previously reduced to a certain degree with propane. By pulsing 4200 pulses or about $7.5 \times 10^{18}$ propane molecules a quite similar reduction degree, $R^{0}=0.23$, was obtained for both catalysts shown in Figure 2. Identical responses of oxygen were obtained over the fully oxidized catalysts, irrespective to the support, while for the partially reduced catalysts, the oxygen response is narrower on the catalyst with a titania intermediate layer. Moreover, the oxygen responses on the fully oxidized catalysts were compared with the Ar one (results not shown). As only minor differences were observed, most probably due to minor differences on diffusion coefficients 

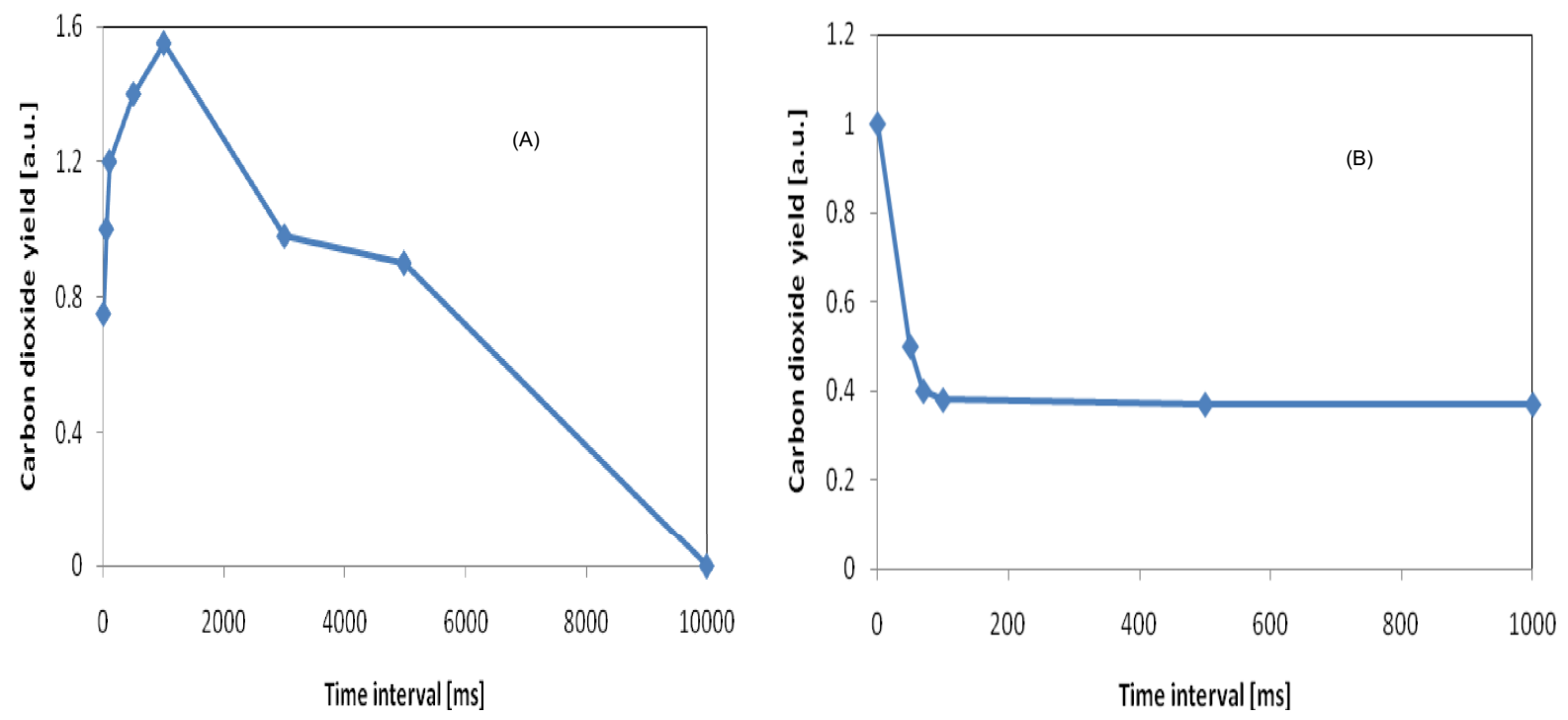

Fig. $3 \mathrm{CO}_{2}$ yield as a function of time interval at $373 \mathrm{~K}$ over $\mathrm{Au} / \mathrm{Ti}(\mathrm{OH})_{4}^{*}$ catalyst and at $773 \mathrm{~K}$ over TiV150 catalyst during alternating pulse experiments in which the oxygen pulse precedes the $\mathrm{CO}$ pulse (A) or propane pulse (B)

of the two species, we concluded that there is no interaction between oxygen and fully oxidized catalyst. The narrower the response, the stronger the interaction. For a better understanding of this behaviour we have to add that our former analysis of reoxidation data over a series of sputtered catalysts with increasing vanadia loading on $\mathrm{TiO}_{x}$ coated beads, reduced by following the same procedure as that used within the present study, confirmed an irreversible dissociative chemisorption of dioxygen (Sack et al., 2004). The reaction rate coefficient increased with increasing V-loading, reaching a maximum value of $1.2 \mathrm{~kg} \mathrm{~m}^{3} /\left(\mathrm{mol}^{2} \cdot \mathrm{s}\right)$ for a vanadia loading of $716 \mu \mathrm{mol} / \mathrm{kg}_{\mathrm{c}}$. As vanadia loading for both $\mathrm{V} 150$ and TiV150 catalysts was lower than this value and the loading of V150 catalyst was higher than that of TiV150 catalyst $\left(490 \mu \mathrm{mol} / \mathrm{kg}_{\mathrm{c}}>314 \mu \mathrm{mol} / \mathrm{kg}_{\mathrm{c}}\right)$, we expected a higher rate coefficient for the reoxidation of V150. However, the simulation results gave a slightly higher value of rate coefficient for TiV150 catalyst than that for V150 catalyst, namely $1.1 \mathrm{~kg}_{\mathrm{Vm}} 3 /\left(\mathrm{mol}^{2} \cdot \mathrm{s}\right)$ against 1.06 $\mathrm{kg}_{\mathrm{V}} \mathrm{m}^{3} /\left(\mathrm{mol}^{2} \cdot \mathrm{s}\right)$. This means that the reducibility of the TiV150 catalyst was slightly higher than that of V150 catalyst. Our results are in good agreement with literature data. It was found that a lower electronegativity of the support cation results in a higher electron density on the bridging $\mathrm{V}-\mathrm{O}$-support bond, which enhances the specific rate of the redox cycle of the catalytic active site (Wachs, 2005).

The shape of the responses of propane, propene or $\mathrm{CO}_{2}$ was not influenced by the support or by the degree of reduction of the catalysts (results not shown). For propane this means that it reacted from the gas phase. As for $\mathrm{CO}_{2}$, this is an evidence of the fact that oxygen from the $\mathrm{V}-\mathrm{O}$-support bond is not directly involved in the catalytic reaction. If this oxygen was involved, the propane, propene and $\mathrm{CO}_{2}$ responses would have been different from TiV150 to V150. However, the oxygen from the V$\mathrm{O}$-support bond influence the reducibility of the system as it can be seen from Figure 2 .

In addition to the TAP results, steady-state experiments evidence as well the beneficial influence of the titania layer on the catalytic activity. The surface TOF (i.e. calculated as activity per outer $\mathrm{V}$ atom) turned out to be twice higher for TiV150 catalyst $\left(0.10 \mathrm{~s}^{-1}\right.$ against 0.05 $\mathrm{s}^{-1}$ ) (Poelman et al., 2007b).

\subsection{Alternating TAP pulse experiments providing ev- idence for intermediates}

2.2.1 Gold catalyst vs. vanadia-based catalysts The type of adsorbed oxygen intermediates and their lifetime was evaluated from the variation of the yield of the produced $\mathrm{CO}_{2}$ with increasing time interval between the alternating pulses, in which $\mathrm{O}_{2}$ is pulsed first followed by $\mathrm{CO}$ or propane. In the case of $\mathrm{CO}$ oxidation at $373 \mathrm{~K}$, the $\mathrm{CO}_{2}$ yield increased with increasing time interval up to $1000 \mathrm{~ms}$ then decreased to almost zero, as shown in Figure 3(A). This tendency confirms the sole participation of adsorbed oxygen and the fact that the lifetime of the adsorbed oxygen species is not longer than $1000 \mathrm{~ms}$. If the lattice oxygen would also be involved in the $\mathrm{CO}$ oxidation, the $\mathrm{CO}_{2}$ yield as a function of time interval would have stayed constant after a certain interval.

In the case of propane oxidation at $773 \mathrm{~K}$, the $\mathrm{CO}_{2}$ yield decreased with increasing time interval up to 70 $\mathrm{ms}$, staying constant for larger intervals. The conversion of propane followed the same course as a function of time interval. This indicates that at very short time intervals, the combustion reaction is promoted by weakly pre-adsorbed oxygen species, while at larger intervals, only lattice oxygen is consumed as both propane conversion and $\mathrm{CO}_{2}$ yield stay constant (Figure 3(B)). We 


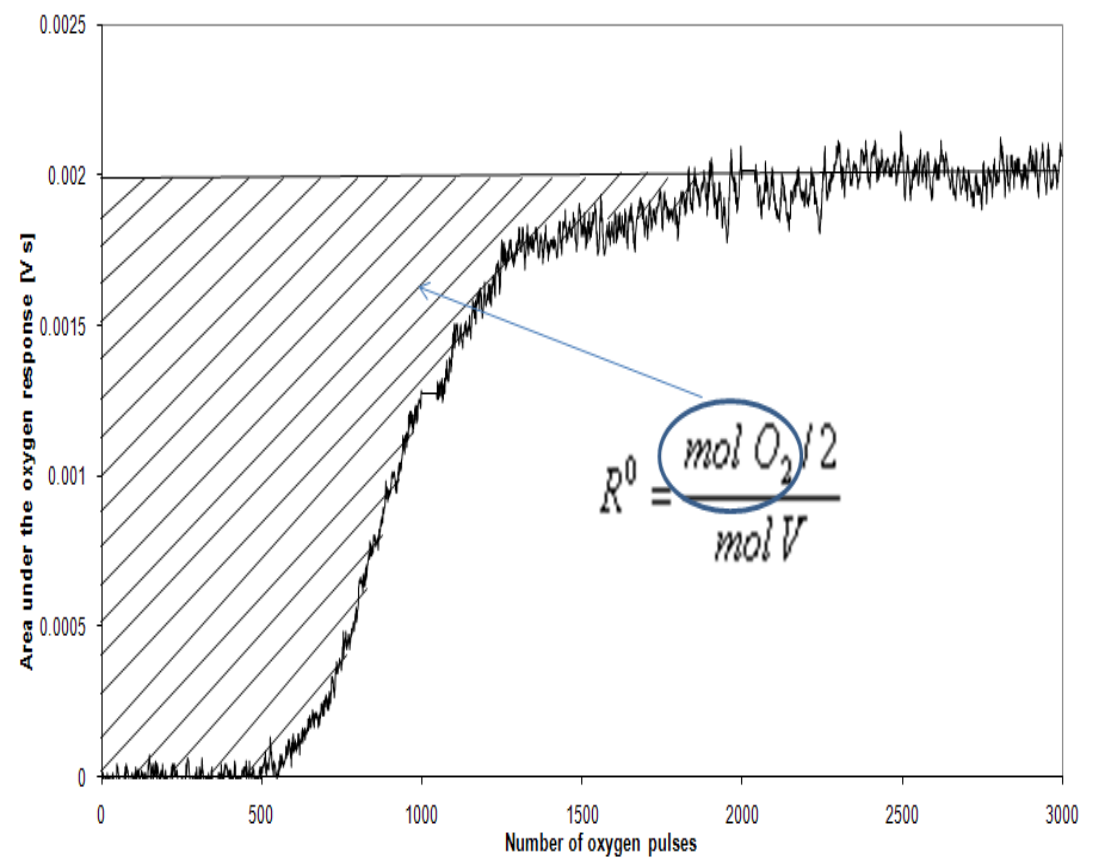

Fig. 4 The area under the oxygen response during oxygen multi-pulse experiments over TiV150 partially reduced catalyst at $773 \mathrm{~K}$

also observed that at high temperatures and over the oxidized surface the direct total oxidation of propane occurs fast followed by fast desorption of $\mathrm{CO}_{2}$. At high temperature over reduced catalyst's surface, the total oxidation of propene becomes more important than the direct total oxidation followed by slow desorption of $\mathrm{CO}_{2}$.

If we compare the behaviour of the two catalysts in respect with alternating pulse experiments, we can conclude that the lifetime of adsorbed oxygen species on the gold catalyst is longer than on the vanadia-based ones. However, apart from the short-lived weakly adsorbed oxygen species, lattice oxygen was preferably responsible for the propane oxidation over vanadia-based catalyst while the oxygen involved in the $\mathrm{CO}$ oxidation was purely adsorbed oxygen.

\subsection{Multi-pulse TAP experiments to assess the degree of reduction of the vanadia-based catalysts}

As alternating pulse experiments evidenced, lattice oxygen was mostly involved in the oxidation process over the vanadia-based catalysts. This implies that the catalysts can be reduced to a certain degree by controlling the number of reducing molecules, i.e. propane in our study. After a number of $7.5 \times 10^{18}$ propane molecules were sent over the catalysts, reoxidation was performed with multi-pulses of oxygen. As shown in Figure 4, the first oxygen pulses were completely consumed by the TiV150 reduced catalyst. Then a fast increase is observed, followed by a leveling off to a constant value. At that point no more oxygen is consumed by the catalyst, indicating that the surface is completely oxidized. The catalysts' state was checked with an oxygen single-pulse experi- ment after every multi-pulses. The area highlighted in Figure 4 was considered as a measure of the total amount of oxygen that was needed to fully reoxidize the catalyst after reduction. This amount is used to calculate the reduction degree. For the catalysts with a vanadia loading time of $150 \mathrm{~min}$, an average reduction degree of 0.23 was obtained by admitting about $7.5 \times 10^{18}$ propane molecules to the catalyst.

The same reduction degree was confirmed from TAP experiments when the completely oxidized catalyst's surface was titrated with propane.

\section{Conclusions}

The most significant result of this study is the resolution of a controversial debate regarding the reaction mechanism of the gold catalyzed CO oxidation. TAP results were considered as the most convincing evidence for molecularly adsorbed oxygen by the scientific community involved in low-temperature $\mathrm{CO}$ oxidation on supported gold catalysts.

Concerning the sputter deposited vanadia catalysts, TAP results were the starting point to further consideration of the effect of the degree of reduction and support upon the mechanism. Detailed kinetic studies are foreseen. This will allow the preparation of highly reproducible catalytic surfaces, which will have wide utility in oxidation reactions for environmental applications.

\section{Acknowledgments}

This work was partially performed in the framework of a Concerted Research Action (GOA) financed by Ghent University. 


\section{Literature Cited}

Bond, G. C.; "Gold: A Relatively New Catalyst," Gold Bull., 34, 117$140(2001)$

Daniells, S. T., A. R. Overweg, M. Makkee and J. A. Moulijn; “The Mechanism of Low-Temperature $\mathrm{CO}$ Oxidation with $\mathrm{Au} / \mathrm{Fe}_{2} \mathrm{O}_{3}$ Catalysts: a Combined Mossbauer, FT-IR, and TAP Reactor Study," J. Catal., 230, 52-65 (2005)

Gleaves, J. T. and J. R. Ebner; "Method and Apparatus for Carrying Out Catalyzed Chemical Reactions and for Studying Catalysts," U.S. Patent 4,626,412 (1986)

Gleaves, J. T., J. R. Ebner and T. C. Kuechler; "Temporal Analysis of Products (TAP) - a Unique Catalyst Evaluation System with Submillisecond Time Resolution," Catal. Rev. Sci. Eng., 30, 49-116 (1988)

Gupta, N. M. and A. K. Tripathi; "Microcalorimetry, Adsorption, and Reaction Studies of $\mathrm{CO}, \mathrm{O}_{2}$, and $\mathrm{CO}+\mathrm{O}_{2}$ over $\mathrm{Fe}_{2} \mathrm{O}_{3}, \mathrm{Au} / \mathrm{Fe}_{2} \mathrm{O}_{3}$, and Polycrystalline Gold Catalysts as a Function of Reduction Treatment," J. Catal., 187, 343-347 (1999)

Haruta, M. and M. Daté; "Advances in the Catalysis of Au Nanoparticles," Appl. Catal., A, 222, 427-437 (2001)

Liu, H., A. I. Kozlov, A. P. Kozlova, T. Shido, K. Asakura and Y. Iwasawa; "Active Oxygen Species and Mechanism for LowTemperature CO Oxidation Reaction on a $\mathrm{TiO}_{2}$-Supported Au Catalyst Prepared from $\mathrm{Au}\left(\mathrm{PPh}_{3}\right)\left(\mathrm{NO}_{3}\right)$ and As-Precipitated Titanium Hydroxide," J. Catal., 185, 252-264 (1999a)

Liu, H., A. I. Kozlov, A. P. Kozlova, T. Shido and Y. Iwasawa; "Active Oxygen Species and Reaction Mechanism for Low-Temperature CO Oxidation Reaction on an $\mathrm{Fe}_{2} \mathrm{O}_{3}$-Supported Au Catalyst Prepared from $\mathrm{Au}\left(\mathrm{PPh}_{3}\right)\left(\mathrm{NO}_{3}\right)$ and As-Precipitated Iron Hydroxide,' Phys. Chem. Chem. Phys., 1, 2851-2860 (1999b)

Olea, M., M. Kunitake, T. Shido, K. Asakura and Y. Iwasawa; "Temporal Analysis of Products (TAP) Study of the Adsorption of CO, $\mathrm{O}_{2}$, and $\mathrm{CO}_{2}$ on a $\mathrm{Au} / \mathrm{Ti}(\mathrm{OH})_{4}^{*}$ Catalyst," Bull. Chem. Soc. Jpn. 74, 255-265 (2001a)

Olea, M., M. Kunitake, T. Shido and Y. Iwasawa; "TAP Study on CO
Oxidation on a Highly Active $\mathrm{Au} / \mathrm{Ti}(\mathrm{OH})_{4}{ }^{*}$ Catalyst," Phys. Chem. Chem. Phys., 3, 627-631 (2001b)

Olea, M., M. Florea, I. Sack, R. P. Silvy, E. M. Gaigneaux, G. B. Marin and P. Grange; "Evidence for the Participation of Lattice Nitrogen from Vanadium Aluminium Oxynitrides in Propane Ammoxidation," J. Catal., 232, 152-160 (2005)

Olea, M., M. Tada and Y. Iwasawa; "Temporal Analysis of Products (TAP) Study on Low Temperature Carbon Monoxide Oxidation on Supported Au Catalysts," Top. Catal., 44, 137-143 (2007)

Peréz-Ramírez, J. and E. V. Kondratenko; "Evolution, Achievements, and Perspectives of the TAP Technique," Catal. Today, 121, 160169 (2007)

Poelman, H., K. Eufinger, D. Depla, D. Poelman, R. De Gryse, B. F. Sels and G. B. Marin; "Magnetron Sputter Deposition for Catalyst Synthesis," Appl. Catal., A, 325, 213-219 (2007a)

Poelman, H., B. F. Sels, M. Olea, K. Eufinger, J. S. Paul, B. Moens, I. Sack, V. Balcaen, F. Bertinchamps, E. M. Gaigneaux, P. A. Jacobs, G. B. Marin, D. Poelman and R. De Gryse; "New Supported Vanadia Catalysts for Oxidation Reactions Prepared by Sputter Deposition," J. Catal., 245, 156-172 (2007b)

Sack, I., M. Olea, H. Poelman, K. Eufinger, R. De Gryse and G. B Marin; "TAP Studies on the Reoxidation of Some Partially Reduced Vanadia-Based Catalysts," Catal. Today, 91-92, 149-153 (2004)

Shekhtman, S. O., G. S. Yablonsky, J. T. Gleaves and R. Fushimi; "'State Defining' Experiment in Chemical Kinetics-Primary Characterization of Catalyst Activity in a TAP Experiment," Chem. Eng. Sci., 58, 4843-4859 (2003)

Wachs, I. E.; "Recent Conceptual Advances in the Catalysis Science of Mixed Metal Oxide Catalytic Materials," Catal. Today, 100, 79-94 (2005)

Yuan, Y., K. Asakura, H. Wan, K. Tsai and Y. Iwasawa; "Supported Gold Catalysts Derived from Gold Complexes and As-Precipitated Metal Hydroxides, Highly Active for Low-Temperature CO Oxidation," Chem. Lett., 755-756 (1996) 